\title{
Sección Informativa
}

\author{
DISCURSO PRONUNCIADO POR EL DOCTOR ANTONIO SOTO-YANCES \\ PRESIDENTE DEL XIV CONGRESO COLOMBIANO DE \\ OBSTETRICIA Y GINECOLOGIA DURANTE EL ACTO INAUGURAL \\ DICIEMBRE 1O. DE 1981
}

I. Es un honor y una grata satisfacción dirigirme a esta docta Asamblea de Médicos Colombianos reunidos en Cartagena de Indias, para cumplir con uno de los objetivos establecidos en los Estatutos de la Federación Colombiana de Sociedades de Obstetricia y Ginecología. Deseo ser el portavoz del agradecimiento de Cartagena y en particular de la Sociedad de Obstetricia y Ginecología de Bolívar, para con la Asamblea General de la Fecolsog, que reunida en Bogotá en diciembre de 1979, depositó en nosotros su confianza para que realizaramos el XIV Congreso Colombiano.

Igualmente deseo manifestar nuestro agradecimiento a mis compañeros de la Junta Directiva de Fecolsog, con el profesor Eduardo Cáceres a la cabeza, por la eficaz y permanente asesoría en la organización de este evento.

Hemos puesto todo nuestro esfuerzo, capacidad $y$ entusiasmo para vencer los 'obstáculos que se han presentado, y tratar de conseguir que este magno evento satisfaga plenamente las aspiraciones científicas y sociales de todos ustedes, que han tenido a bien honrrarnos con su amable participación, abandonando sus responsabilidades profesionales y la tranquilidad de sus hogares para dar brillo con sus conocimientos y experiencias a esta reunión. Reciban todos la más cordial, sincera y fraternal bienvenida. $Y$ hago votos porque su permanencia en el corralito de piedra sea en todo momento grata y provechosa.

II. Permitanme hacer algunas observaciones pertinentes al programa científico, cuidadosamente seleccionado bajo la dirección acuciosa del Dr. Jaime Barrios Amaya:

A. Los cursillos pre-congresos desarrollados por profesores extranjeros de eximias calidades académicas, reconocidas a nivel mundial, brindaron a sus asistentes los últimos adelantos científicos $y$ tecnológicos en áreas de la perinatología - Ginecología Endocrina - Métodos prácticos de laboratorio en GinecoObstetricia y Patología Mamaria.

B. Los temas oficiales pretenden: EI primero, sobre atención maternoinfantil, presentar la realidad actualizada de esta problemática en Colombia y presentar recomendaciones que redunden en beneficio de la madre $y$ el niño colombianos, centro de nuestro estudio y preocupación. El segundo, sobre Patología Mamaria, involucrar este órgano, definitivamente ginecológico, a nuestra especialidad y puede considerarse este congreso como la plataforma 
de rescate, ya que por primera vez se presenta como tema oficial en congresos nacionales.

C. En las conferencias especiales, que serán dictadas por eminentes profesores de diferentes nacionalidades, estamos seguros de obtener la más abundante y valiosa información científica derivada de su gran experiencia y conocimiento sobre temas de actualidad. A todos estos ilustres catedráticos quiero presentar nuestros más sinceros agradecimientos por haber aceptado viajar de tan distantes lugares y estar en este momento con nosotros.

D. Los temas libres permitiran a sus autores presentar aportes cient íficos de alta calidad, reflejo de los trabajos e investigaciones que se realizan en nuestro país, especialmente en las facultades de medicina.

11I. Sería injusto olvidar en esta noche a aquellos profesores que en nuestro medio marcaron derroteros en el ámbito académico de la Gineco-Obstetricia, tales como los Dres. Rafael Calvo Castaño y Napoleón Franco Pareja, iniciadores de las Cátedras respectivas en la Facultad de Medicina, posteriormente Ios Doctores Juan Barrios Zapata y Andrés Guillermo Tarra, quienes continuaron la labor ardua y difícil, diría yo quijotesca, de los anteriores.

Más recientemente, los Dres. Antonio María Martínez Escobar y Gerardo Chadid Samur, ambos fallecidos, quienes siguieron marcando hitos en la práctica privada el primero $y$ en la docencia el segundo. $Y$ en la época inmediatamente anterior los Dres. Hernando Taylor Enriquez, quien aún sigue impartiendo cátedra de alta calidad científica y Jorge Milanés Pernett, maestro y forjador de una escuela indómita $y$ tesonera de obstetras y a quien quiero hoy publica- mente rendir el tributo filial de mi más sincera admiración y respeto.

IV. Igualmente deseo rendir homenaje de imperecedero recuerdo al eminentísimo profesor Doctor Roberto Caldeyro-Barcia, maestro de maestros, de quien sentimos positivo orgullo de tenerlo entre nosotros y quien con su sabia dirección moldeó en Montevideo nuestros conocimientos en perinatología, así como los de muchos de los aquí presentes.

V. Con toda justicia y sinceridad quiero dejar constancia de mi eterna gratitud para todos los miembros del comité organizador, Dres. Oscar Rodgers, Benjamín Blanco, Raúl Vargas, Juan Martínez, Manuel Rodríguez, Víctor Hernández, Jaime Barrios, Aníbal Perna, Alvaro Ramos y Boris Calvo, quienes demostraron el mayor espíritu de trabajo, entusiasmo y sacrificio en el cumplimiento de las funciones encomendadas; ellos han hecho posible esta reunión.

Espero que el programa social, organizado bajo la dirección persistente $y$ laboriosa del profesor Aníbal Perna Mazzeo, sea del agrado de los asistentes y que satisfaga sus aspiraciones de descanso y esparcimiento.

Capítulo aparte merece la abnegada $y$ eficaz actividad del comité femenino, bajo la dirección de la Sra. Yadira de Rodgers, quienes han preparado un atractivo programa para vuestras esposas y acompañantes. Para ellas el testimonio de mi más recóndito y sincero agradecimiento.

VI. Me es grato hacer constar, en nombre del Comité Organizador, nuestro agradecimiento al Gobierno Nacional, al Ministerio de Salud Pública, al Departamento de Bolívar, al Municipio de Cartagena, a los laboratorios farma- 
ceúticos, casas productoras de equipos médicos o personas que en una u otra forma han hecho posible la realización de este evento científico, que nos ha permitido reunir bajo este cielo tropical, diáfano y acogedor, dispuestos a entregar y recibir nuevos conocimientos, intercambiar ideas y experiencias, establecer o renovar contactos personales $y$ amistades que muchas veces facilitan colaboraciones multinacionales en aspectos profesionales de interés mutuo.

VII. Por último, siento la necesidad de manifestar mi reconocimiento hacia la que en vida fue mi esposa y quien me acompañó hasta la mitad del camino; ella de quien alguna vez dijo mi maestro Jorge Milanes: "Ha de ser tu pedestal o tu lápida", supo en vida rodearme de la felicidad, comprensión y calor necesarios para poder trabajar, estudiar y progresar, y luego de su partida definitiva cumpliendo el designio natural de todos los mortales, transfundió en mí el valor y la fuerza necesarias para seguir en la dura tarea encomendada; por ello reconozco, que en lo que atañe a mí labor personal, los méritos si los hubiere, se deben a la imborrable memoria de Rita de Soto-Yances.

Mil gracias 